Article

\title{
Lifetime and Fluorescence Quantum Yield of Two Fluorescein-Amino Acid-Based Compounds in Different Organic Solvents and Gold Colloidal Suspensions
}

\author{
Viviane Pilla ${ }^{1,2, *}$, Augusto C. Gonçalves ${ }^{1,3}$, Alcindo A. Dos Santos ${ }^{3}$ and Carlos Lodeiro ${ }^{1,4}$ (i) \\ 1 BIOSCOPE Group, LAQV-REQUIMTE, Chemistry Department, Faculty of Science and Technology, \\ University NOVA of Lisbon, 2829-516 Caparica, Portugal; aucegon@gmail.com (A.C.G.); cle@fct.unl.pt (C.L.) \\ 2 Instituto de Física, Universidade Federal de Uberlândia-UFU, Av. João Naves de Ávila 2121, \\ 38400-902 Uberlândia, Brazil \\ 3 Instituto de Química, Universidade de São Paulo-USP, Av. Prof. Lineu Prestes 748, CxP 26077, \\ 05508-000 São Paulo, Brazil; alcindo@iq.usp.br \\ 4 Proteomass Scientific Society, Rua dos Inventores, Madan Park, 2829-516 Caparica, Portugal \\ * Correspondence: vivianepilla@ufu.br
}

Received: 11 May 2018; Accepted: 28 June 2018; Published: 30 June 2018

\begin{abstract}
Fluorescein and its derivatives are yellowish-green emitting dyes with outstanding potential in advanced molecular probes for different applications. In this work, two fluorescent compounds containing fluorescein and an amino acid residue (compounds $\mathbf{1}$ and $\mathbf{2}$ ) were photophysically explored. Compounds $\mathbf{1}$ and $\mathbf{2}$ were previously synthesized via ester linkage between fluorescein ethyl ester and Boc-ser (TMS)-OH or Boc-cys(4-methyl benzyl)-OH. Studies on the time-resolved fluorescence lifetime and relative fluorescence quantum yield $(\phi)$ were performed for $\mathbf{1}$ and $\mathbf{2}$ diluted in acetonitrile, ethanol, dimethyl sulfoxide, and tetrahydrofuran solvents. The discussion considered the dielectric constants of the studied solvents (range between 7.5 and 47.2) and the photophysical parameters. The results of the lifetime and $\phi$ were compared with those obtained for compounds 1, 2 and fluorescein without an amino acid residue in alkaline aqueous solutions. Moreover, as a preliminary result compound $\mathbf{2}$ (S-cysteine) was tested in the presence of gold nanoparticles as an aggregation colorimetric probe.
\end{abstract}

Keywords: fluorescein; lifetime; fluorescence quantum yield; gold nanoparticles

\section{Introduction}

One of the most commonly yellowish-green emitting dyes used for the preparation of advanced molecular probes applied in biological, toxicological, biomedical, and environmental studies is fluorescein [1-4]. It is a very versatile dye due to its attractive photophysical properties, such as high extinction coefficients, high fluorescence quantum yield $(\phi)$, biocompatibility and low cost [5-7]. Fluorescein and its derivatives can be found as differently charged species depending on the $\mathrm{pH}$ of the aqueous solution. The range of these species progresses through the protonated cation form (acidic solution, $\left.\mathrm{FH}_{3}^{+}\right)$to the neutral species $\left(\mathrm{FH}_{2}\right)$ and then to the anionic $\left(\mathrm{FH}^{-}\right)$and the dianionic $\left(\mathrm{F}^{2-}\right)$ entities in alkaline solutions $[5,8,9]$.

As a result of the electron distribution around the fluorescein core, these different entities possess unique photophysical properties that affect the absorbed and emitted light. The other photophysical parameters, such as the quantum yield and the lifetimes of the excited states, are also closely related to the $\mathrm{pH}[9,10]$, polarity $[11,12]$, and hydrogen bonding power (HBP) $[13,14]$ of the 
chemical environment [8]. The solvent polarity determines the equilibrium form of fluorescein and its derivatives; for example, in polar protic solvents, dissociation of the acidic phenol hydrogen $(\mathrm{pKa}=6.4$ in water) leads to an equilibrium between the neutral and anionic forms; in contrast, the predominant form in aprotic solvents is the neutral lactone [8]. To characterize the solvatochromism, fluorescein was extensively explored using absorption, steady-state, and time-resolved fluorescence spectroscopy $[6,11,15-18]$. The absorption/emission band shifts exhibited a high dependence on the HBP and dielectric constants of the solvents $[13,14,19]$. Consequently, the solvent-dependent photophysical characterization of new chromophores must be performed with differing solvents $[20,21]$ to establish diverseness to suit a variety of potential applications.

Fluorescein in its free-acid form is a very versatile fluorogenic building block for the synthesis of new molecular probes [22]. However, due to the presence of oxygenated organic functional groups over the core of the molecule, fluorescein is poorly selective for a specific analyte. The outermost groups around the xanthene moiety can be structurally modified using biomolecules (such as amino acids or peptides) to adjust the chromophore properties to suit the desired analytical application $[4,22]$.

Recent studies have highlighted the potential of fluorescein as a fluorescent compound for functionalizing gold nanoparticles (Au-NPs), and preparation of smart materials. Several applications have been reported as in sensitive detection of toxins [23]; in vitro and in vivo breast cancer imaging [24]; the detection of immunoglobulin G [25]; a dual-mode imaging system [26]; selective recognition and quantitative detection of thiourea [27]; tumor suppressor (p53) detection using time-resolved fluorescence [28]; intracellular $\mathrm{pH}$ mapping and cellular $\mathrm{pH}$ measurement under drug stimulation [29]; an optical mercury chemosensor [30]; and other nanoarchitecture materials for drug delivery [31]. With these applications in mind, we have designed and synthesized two compounds, 1 and $\mathbf{2}$ (Figure 1) by a simple esterification reaction of the phenolic portion with the protected amino acids Boc-Ser (TBDMS)-OH and Boc-Cys (4-methyl-benzyl)-OH, respectively. Both compounds, $\mathbf{1}$ and 2 were explored recently by us, as probes for the trivalent ions $\left(\mathrm{Al}^{3+}, \mathrm{Fe}^{3+}, \mathrm{Ga}^{3+}\right.$, and $\left.\mathrm{Cr}^{3+}\right)$ as well as for $\mathrm{Hg}^{2+}$ [22].

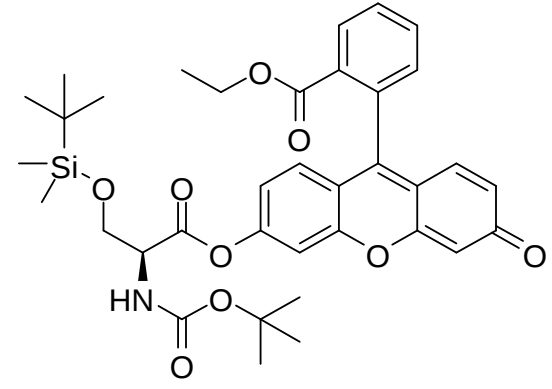

1

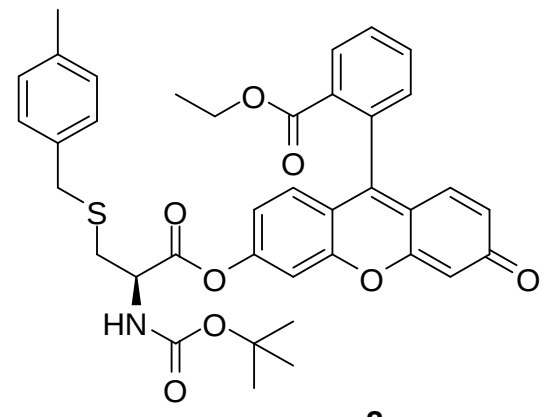

2

Figure 1. Chemical structure of compounds 1 and 2.

In order to explore the interaction with different organic solvents and colloidal suspensions, the present work reports the solvent effect on the UV-vis absorption, steady-state fluorescence, and time-resolved fluorescence spectroscopy, and the relative fluorescence quantum yield, $\phi$, of compounds 1 and 2. These studies were performed in four different solvents, acetonitrile, dimethylsulfoxide (DMSO), tetrahydrofuran (THF), and absolute ethanol. For fluorescein without an amino acid residue, the spectroscopic, lifetime, and $\phi$ results in alkaline aqueous solutions are reported for comparison. To evaluate the effects of the presence of a sulfur atom in 2 , its interaction with gold nanoparticles in an ethanolic colloidal suspension was also performed. 


\section{Materials and Methods}

Chemicals, starting materials, and synthesis of gold nanoparticles. Fluorescein (free acid) was purchased from Fluka. Compounds $\mathbf{1}$ and $\mathbf{2}$ were prepared as reported previously [22] and presented in the Supplementary Materials. Acetonitrile, dimethylsulfoxide (DMSO), tetrahydrofuran (THF), and ethanol were purchased from Sigma Aldrich and used as received. The alkaline aqueous solution was prepared using $0.064 \mathrm{M} \mathrm{NaOH}$ ( $\mathrm{pH}$ 12.8). The Au-NPs used in this study were obtained in absolute ethanol (absorbance of 1.23 at $535 \mathrm{~nm}$ and NP size of $48 \mathrm{~nm}$ ) using a patented technique that was published recently [32].

Instruments: Absorption spectra were recorded on a Jasco V-650 spectrophotometer, and fluorescence emission spectra were obtained using a Horiba-Yvon-Spex Fluoromax- 4 spectrofluorimeter. The lifetime of the excited state was measured using a Horiba Jobin-Yvon Tempro equipped with a NanoLED light source at $460 \mathrm{~nm}$ at the PROTEOMASS Scientific Society Facility, Portugal. Dynamic light scattering (DLS) equipment was used to determine the particle surface charge Z-potential (Zetasizer Nano ZS from Malvern Instruments, Malvern, UK).

Spectrophotometric and spectrofluorimetric measurements. Stock solutions of $\mathbf{1}$ and $\mathbf{2}$ were prepared separately by diluting an appropriate amount of compound $\mathbf{1}$ or $\mathbf{2}$ in different solvents (acetonitrile, ethanol, DMSO, THF or alkaline aqueous solution) in $10 \mathrm{~mL}$ volumetric flasks. Working solutions of compounds $\mathbf{1}$ and $\mathbf{2}$ were prepared by diluting the stock solutions in their respective solvent (acetonitrile, ethanol, DMSO, THF or alkaline aqueous solution) to obtain a final concentration of $1 \times 10^{-5} \mathrm{~mol} / \mathrm{L}$. The fluorescence quantum efficiencies of compounds 1 and 2 were measured with a solution of acridine yellow in absolute ethanol as the standard ( $\phi=0.47)$ [33] and were corrected for the different refraction indexes of the solvents. The Au-NP functionalization was performed by diluting compound 2 (concentration of $1.67 \times 10^{-4} \mathrm{~mol} / \mathrm{L}$ ) in $4 \mathrm{~mL}$ of an ethanol suspension. Next, $1 \mathrm{~mL}$ of the mixture was homogenized in an ultrasonic bath for $5 \mathrm{~min}$, and the other $3 \mathrm{~mL}$ was kept under stirring for $20 \mathrm{~h}$. Both samples were washed twice with ethanol (centrifuged at $4000 \mathrm{rpm}$ for $10 \mathrm{~min}$ ), and the functionalized NPs were finally suspended in ethanol before the photophysical characterization.

\section{Results and Discussion}

Figure 2 shows compound 1 suspended in the different solvents, acetonitrile, ethanol, dimethylsulfoxide (DMSO), and tetrahydrofuran (THF). The dielectric constants of these solvents differ (Table 1) [17,34]. The average emission wavelength for compound 1 prepared in THF, ethanol, acetonitrile, and DMSO was 510, 555, 559, and $560 \mathrm{~nm}$, respectively. The absorption and emission data of compounds $\mathbf{1}$ and $\mathbf{2}$ in THF, ethanol, acetonitrile, and DMSO are presented in Table 1. Absorption and emission spectra for compound 2 are reported in the Supplementary Materials (Figure S1).

Table 1. UV-vis and fluorescence data for $\mathbf{1}$ and $2\left(1 \times 10^{-5} \mathrm{~mol} / \mathrm{L}\right)$ in tetrahydrofuran (THF), ethanol, acetonitrile, and dimethylsulfoxide (DMSO).

\begin{tabular}{|c|c|c|c|c|c|c|c|c|}
\hline & Solvent & $\begin{array}{c}\mathrm{UV}-\mathrm{vis} \lambda_{\mathrm{abs}} \\
(\mathrm{nm})\end{array}$ & $\log \varepsilon$ & $\begin{array}{l}\text { Fluorescence } \\
\lambda_{\mathrm{em} \max }(\mathrm{nm})\end{array}$ & $\begin{array}{l}\text { Stokes shift } \\
(\mathrm{nm})\end{array}$ & $\begin{array}{l}\text { Quantum } \\
\text { Yield } \phi\end{array}$ & Lifetime $\tau_{1}$ (ns) & $\begin{array}{c}\text { Dielectric } \\
\text { Constant }\left(\varepsilon_{\mathrm{r}}\right)\end{array}$ \\
\hline \multirow{4}{*}{1} & THF & 428 & 4.10 & 512 & 84 & 0.003 & $2.3 \pm 0.2$ & 7.52 \\
\hline & Ethanol & 433 & 4.10 & 525 & 92 & 0.048 & $3.65 \pm 0.02$ & 24.3 \\
\hline & Acetonitrile & 445 & 4.12 & 542 & 97 & 0.003 & $2.7 \pm 0.1$ & 36.6 \\
\hline & DMSO & 449 & 4.06 & 547 & 98 & 0.010 & $4.03 \pm 0.02$ & 47.2 \\
\hline \multirow{4}{*}{2} & THF & 431 & 4.01 & 518 & 87 & 0.006 & $2.49 \pm 0.05$ & 7.52 \\
\hline & Ethanol & 435 & 3.89 & 516 & 81 & 0.043 & $3.29 \pm 0.03$ & 24.3 \\
\hline & Acetonitrile & 431 & 4.01 & 521 & 90 & 0.004 & $2.97 \pm 0.08$ & 36.6 \\
\hline & DMSO & 457 & 4.04 & 549 & 92 & 0.025 & $4.06 \pm 0.02$ & 47.2 \\
\hline
\end{tabular}




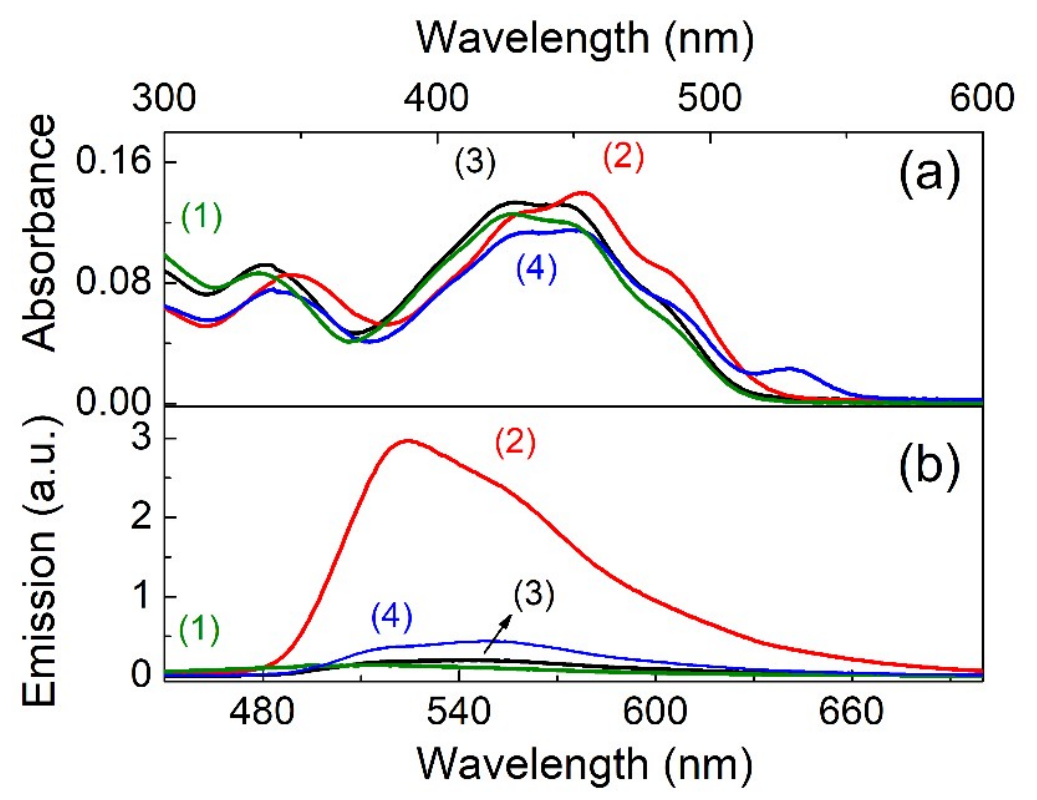

Figure 2. (a) Absorbance and (b) emission spectra of compound 1 in different solvents (concentration of $1 \times 10^{-5} \mathrm{~mol} / \mathrm{L}$ ): (1) Tetrahydrofuran (THF), (2) ethanol, (3) acetonitrile, and (4) dimethylsulfoxide (DMSO).

As shown in Table 1, the dielectric constants $\left(\varepsilon_{\mathrm{r}}\right)$ of the studied solvents ranged from 7.52 (THF) to 47.2 (DMSO). The observed molar absorptivity values of $\mathbf{1}$ and $\mathbf{2}$ did not vary appreciably in the different solvents and thus could not be correlated with a solvent effect. Figure 3a presents the peak absorbance $\left(\lambda_{\mathrm{abs}}\right)$ of compounds 1 and $\mathbf{2}$ versus the dielectric constant of the various solvents, and a bathochromic shift in absorption peak was observed as a function of $\varepsilon_{\mathrm{r}}$ in both compounds. In compound 2, a deviation from the expected trend of increase was observed between ethanol and acetonitrile (Figure 3a). This finding can be rationalized regarding the prevailing type of force underlying the compound/solvent interaction. The sulfur atom amino acid side chain in $\mathbf{2}$ is poorly electronegative; thus, ethanol (a protic solvent) is better able to stabilize the compound via its HBP and solvation than acetonitrile, which acts through dipole-dipole interactions [14,35].

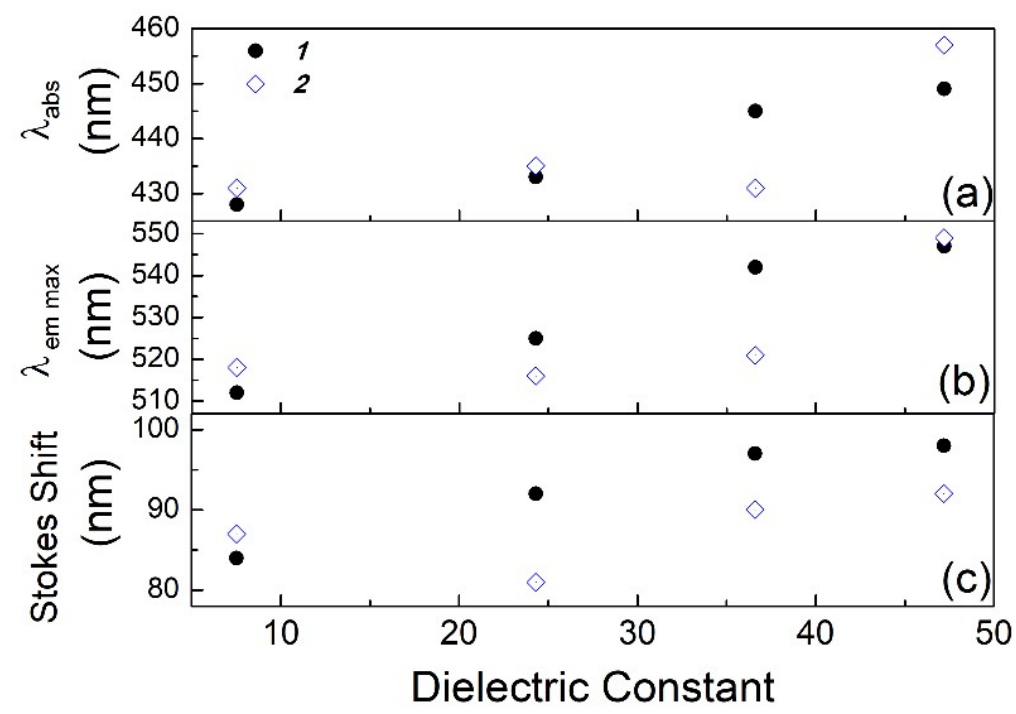

Figure 3. $\lambda_{\mathrm{abs}}(\mathbf{a}), \lambda_{\mathrm{em} \max }(\mathbf{b})$ and the Stokes shift (c) in function of the dielectric constant for compounds $\mathbf{1}$ and $\mathbf{2}$ are presented for different solvents. 
Figure $3 b, c$ shows, the peak emission $\left(\lambda_{\text {em max }}\right)$ and the Stokes shift of compounds $\mathbf{1}$ and 2 as a function of the dielectric constant. The results show an expected trend of increase in the Stokes shift and $\lambda_{\text {em max }}$ as the solvent polarity increases. Chromophores present a larger dipole moment in the excited state than in the ground state, especially for polar or highly functionalized chromophores, such as fluorescein $[36,37]$. Consequently, after excitation, the solvent dipoles can reorient around the excited state of the chromophore, lowering its energy. Thus, the energy difference between the excited and ground states is lower in DMSO than in THF. Also, several studies correlated solvent parameters (such as dielectric constant and refractive index) with the spectral Stokes shift [19,36,37]. The redshift of the fluorescence bands has been attributed to the difference between the charge distributions of the excited and ground states in the solvent, i.e., a stronger interaction in the excited states can occur with polar solvents [38].

In addition, the absorbance and fluorescence spectra of compounds $\mathbf{1}$ and $\mathbf{2}$ and free fluorescein in alkaline aqueous solution ( $\mathrm{pH} 12.8$ ) are typical of the dianion form [8,9,39], the experimental spectra are shown at Figure S2. The average emission value for all compounds is (529.3 \pm 0.6$) \mathrm{nm}$ and the peak emission is $(512.3 \pm 0.6) \mathrm{nm}$. These results are in agreement with the reports of a maximum emission from 510 to $520 \mathrm{~nm}$ [9] and corroborate the results of our previous study [22]. The addition of water disrupted the amino acid functionalization of fluorescein (acetonitrile with $\sim 9 \%-50 \%$ water in the presence of $\mathrm{Hg}^{2+}$ ), and in the present study, compounds $\mathbf{1}$ and $\mathbf{2}$ in aqueous solutions were mainly found in the dianion form. Therefore, the aqueous alkaline solution was not considered when studying the dependence on the solvent used to suspend compounds $\mathbf{1}$ and $\mathbf{2}$.

For both compounds ( $\mathbf{1}$ and $\mathbf{2}$ ), time-resolved photoluminescence spectroscopy was performed to measure the lifetime of the excited state, and experimental setup is presented as Supplementary Materials. Figure 4 presents the transient measurement obtained for compound $\mathbf{1}$ in different solvents. For the solvents THF, ethanol, acetonitrile, and DMSO, the fluorescence decays were fitted with a double exponential law with a $\chi^{2}$ value less than 1.2 for compounds 1 and 2 . These results suggest the presence of two different species in the excited state, which are attributed to the planar and perpendicular conformations of the xanthene relative to the benzene moiety [22,40]. The average lifetime values of compounds $\mathbf{1}$ and $\mathbf{2}$ in different solvents are presented in Table 2. Similarly, to the peak absorption and the Stokes shift, the lifetime values were also dependent on the solvent polarity and ranged from 2.3 ns to 4.06 ns. A deviation of the increasing trend was observed between ethanol and acetonitrile, because in this case, the excited state was more efficiently stabilized by the HBP in the ethanol solution than in acetonitrile, causing an increase in the lifetime. Also, for the neutral lactone form of fluorescein, the lifetime of the free acid varied between 2.5 and 3.4 ns for the same set of solvents. The exciton lifetimes of fluorescein and its derivatives in different solvents have been reported elsewhere $[13,18]$.

Table 2. Lifetime results for compound 1 and compound 2 in different solvents $\left(\lambda_{\mathrm{e}}=460 \mathrm{~nm}\right)$. The lifetimes were obtained by fitting to $A+B 1 \times \operatorname{Exp}\left(-t / \tau_{1}\right)+B 2 \times \operatorname{Exp}\left(-t / \tau_{2}\right)$.

\begin{tabular}{|c|c|c|c|c|c|c|}
\hline & \multicolumn{3}{|c|}{ Compound 1} & \multicolumn{3}{|c|}{ Compound 2} \\
\hline & $\tau_{1}(\mathrm{~ns})$ & $\tau_{2}(\mathrm{~ns})$ & \multirow{2}{*}{$x^{2}$} & $\tau_{1}(\mathrm{~ns})$ & $\tau_{2}(\mathrm{~ns})$ & \multirow{2}{*}{$x^{2}$} \\
\hline & B1 (Rel. Amp.\%) & B2 (Rel. Amp.\%) & & B1 (Rel. Amp.\%) & B2 (Rel. Amp.\%) & \\
\hline THF & $2.3 \pm 0.2$ & $0.08 \pm 0.02$ & $0.98 \pm 0.09$ & $2.49 \pm 0.05$ & $0.110 \pm 0.005$ & $1.01 \pm 0.09$ \\
\hline$\left(\mathrm{C}_{4} \mathrm{H}_{8} \mathrm{O}\right)$ & 1.9 & 98.1 & & 3.3 & 96.7 & \\
\hline Ethanol & $3.65 \pm 0.02$ & $0.788 \pm 0.009$ & $1.01 \pm 0.04$ & $3.29 \pm 0.03$ & $0.90 \pm 0.06$ & $1.1 \pm 0.1$ \\
\hline$\left(\mathrm{C}_{2} \mathrm{H}_{6} \mathrm{O}\right)$ & 40 & 60 & & 93 & 7 & \\
\hline Acetonitrile & $2.70 \pm 0.06$ & $0.231 \pm 0.006$ & $1.03 \pm 0.08$ & $2.97 \pm 0.08$ & $0.357 \pm 0.003$ & $1.0 \pm 0.1$ \\
\hline$\left(\mathrm{CH}_{3} \mathrm{CN}\right)$ & 5.6 & 94.4 & & 6 & 94 & \\
\hline DMSO & $4.03 \pm 0.02$ & $0.13 \pm 0.08$ & $1.09 \pm 0.07$ & $4.06 \pm 0.02$ & $0.65 \pm 0.02$ & $1.02 \pm 0.07$ \\
\hline$\left(\left(\mathrm{CH}_{3}\right)_{2} \mathrm{SO}\right)$ & 79 & 21 & & 48 & 52 & \\
\hline
\end{tabular}




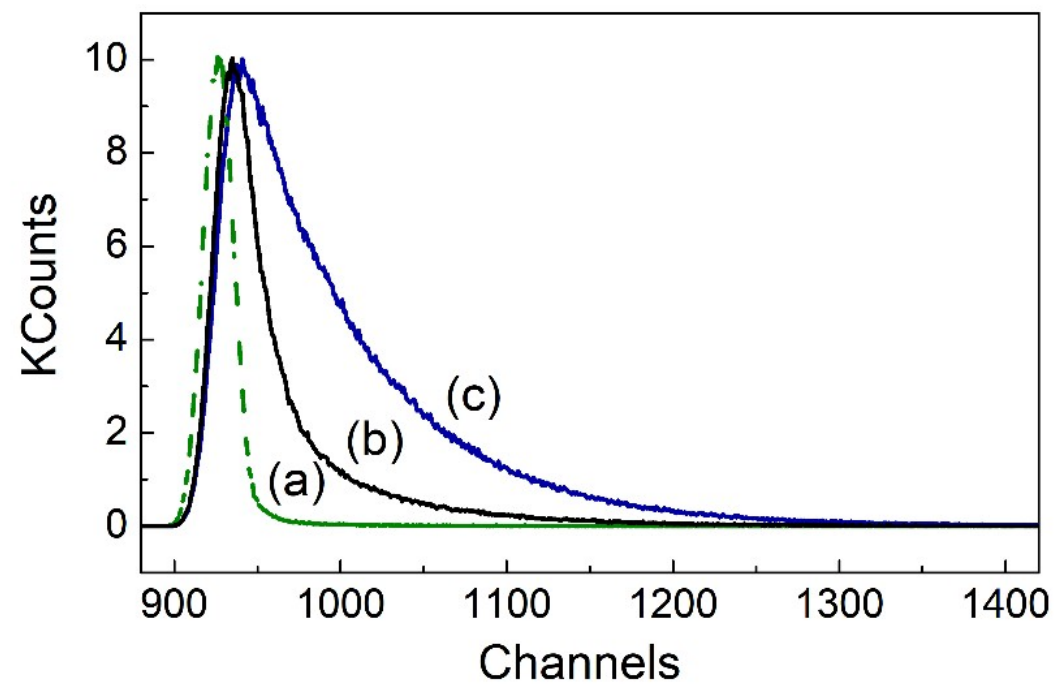

Figure 4. Lifetime measurements of compound 1 in THF (a), ethanol (b) and alkaline aqueous solutions (c) (concentration of $1 \times 10^{-5} \mathrm{~mol} / \mathrm{L}$ ). The time calibration is $5.487 \times 10^{-11} \mathrm{~s} / \mathrm{ch}$.

For comparison, the free fluorescein in alkaline aqueous solution ( $\mathrm{pH} 12.8)$, the transient emission was a good fit with just a single exponential with a value of $(4.06 \pm 0.01) \mathrm{ns}$ and $\chi^{2}=(1.1 \pm 0.1)$, in agreement with the reported results. For example, for the sodium fluorescein dianion, the value was $4.16 \mathrm{~ns}$ [21]; for fluorescein in $0.1 \mathrm{M}$ and $0.01 \mathrm{M} \mathrm{NaOH}$, the values were $4.02 \mathrm{~ns}$ [41], and (4.0 \pm 0.2$)$ ns [13], respectively. For compounds $\mathbf{1}$ and $\mathbf{2}$ in alkaline aqueous solution ( $\mathrm{pH}$ 12.8), the fluorescence transients, as expected, also fit well with just one exponential (Figure 4c), and the obtained lifetimes were $(4.06 \pm 0.01)$ ns and $(4.08 \pm 0.02)$ ns, respectively.

In addition, the relative quantum yield of fluorescence was determined for both compounds; the results are presented in Figure $5 \mathrm{a}$ as a function of the dielectric constant of the solvents. However, the $\phi$ values for compounds $\mathbf{1}$ and $\mathbf{2}$ and fluorescein in THF, acetonitrile, and DMSO were low, in agreement with the results of other studies of fluorescein and its derivatives $[2,6,12,18]$. The decreases of $\phi$ values for fluorescein derivatives have been reported and attributed to the photoinduced electron transfer due to a group linked to the fluorophore of the xanthene or phenyl ring [42]. Figure $5 \mathrm{~b}$ shows the behavior for the lifetime and $\phi$ of compound 2 as a function of the dielectric constant.

The $\phi$ values for 1, 2 and fluorescein in different solvents (THF, acetonitrile, and DMSO) do not seem to exhibit any polarity-based relationship $(0.3 \%-2.5 \%$, Table 1$)$. However, in ethanol, the quantum yield was significantly higher ( $4.8 \%$ and $4.3 \%$ for 1 and 2 , respectively, Table 1$)$, which is attributed to the protic character of the solvent and the presence of water. This attribute contributes to the stabilization of the excited states and molecular symmetry, preventing non-radiative decay $[43,44]$. In addition, higher $\phi$ values were obtained for fluorescein and compounds $\mathbf{1}$ and $\mathbf{2}$ in alkaline aqueous solutions ( $\mathrm{pH} 12.8)$, in good agreement with the values reported in the literature $(72 \%)[45,46]$.

Finally, as a preliminary study, compound 2 was explored in the presence of a gold colloidal solution. A previously synthesized Au-NPs colloidal solution suspended in absolute ethanol [32] was added to a solution of $\mathbf{2}$. The emission of compound $\mathbf{2}$ was wholly quenched, as a result of the substantial energy transfer between the metal core and the chromophore [47]. This result confirms the charge interaction between compound 2 and the Au-NPs surface. Additionally (Figure 6), a new absorption band appeared at c.a. $650 \mathrm{~nm}$ with a positive Z-potential. This finding is consistent with the formation of a nanostructured chain due to the aggregation effect upon interaction of the chromophore to the metal core [30,47]. The color of the solution changed from red to purple confirming the aggregation of this system. The positive Z-potential determined after ligand interaction $(23.3 \mathrm{mV}$ and $16.9 \mathrm{mV}$ ), suggests the formation of a destabilized solution (Figure $6 \mathrm{~b}, \mathrm{c}$ ). These results indicate that the Au-NPs interacted via surface charge variation with the S-cysteine functionalized fluorescein, 
which provided reduced colloidal stability $[48,49]$. For comparison, Au-NPs successfully coated with a positively charged capping layer of L-cysteine methyl ester hydrochloride show positive Z-potential between 33.2 and $49 \mathrm{mV}$ dependent on the NPs and hydrodynamic diameters, indicating their electrostatic stability [50].

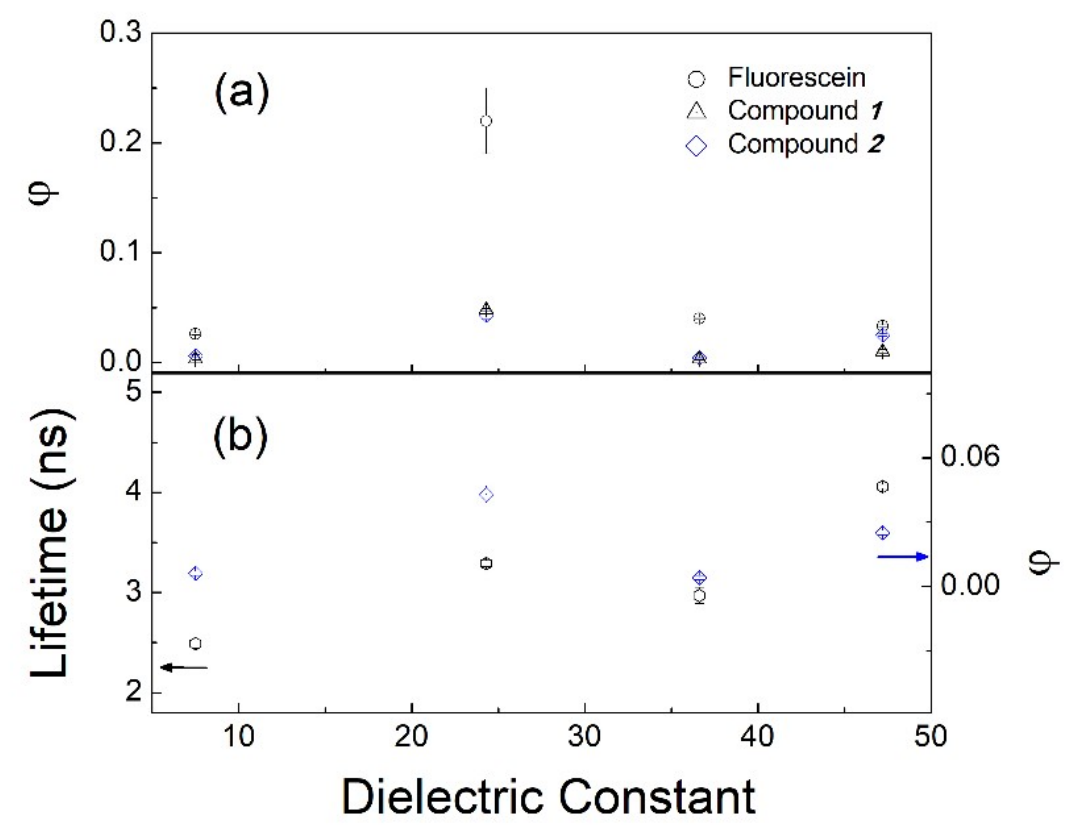

Figure 5. (a) Relative quantum yield of compounds 1, 2 and fluorescein at $\lambda_{\mathrm{e}}=(432 \pm 7) \mathrm{nm}$ as a function of the dielectric constant. (b) Lifetime and $\phi$ of compound 2.

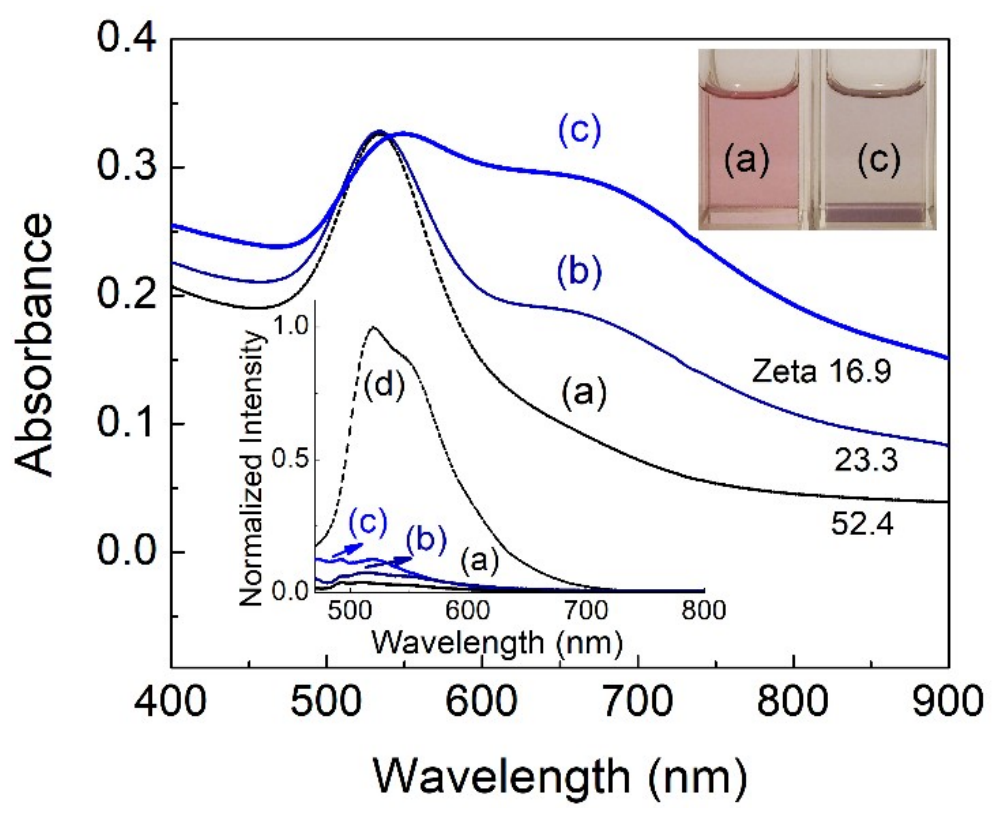

Figure 6. (a) Absorbance spectra of Au-NPs in ethanol and of centrifuged compound 2 homogenized with Au-NPs for (b) 5 min with sonication and (c) with $20 \mathrm{~h}$ of magnetic stirring. The insets show the emission for $(\mathbf{a}-\mathbf{c})$ and compound 2 in ethanol $\left(1 \times 10^{-5} \mathrm{~mol} / \mathrm{L}\right)(\mathbf{d})$ at $\lambda_{\mathrm{e}}=430 \mathrm{~nm}$ and the Z-potential values (Zeta in $\mathrm{mV}$ ). 


\section{Conclusions}

The spectroscopic characteristics, lifetime, and fluorescence quantum efficiency of two fluorescein derivatives in different solvents were successfully determined. The absorbance, emission, and lifetime measurements showed a slight dependence on the dielectric constant of the solvent. The relative quantum efficiency was determined, and the results do not seem to indicate any relationship with the solvent polarity. However, in ethanol, the quantum efficiency was far higher $(\sim 4.8 \%$ and $4.3 \%$ for 1 and $\mathbf{2}$, respectively), which is attributed to the protic character of the solvent. Finally, compound 2 was employed to explore in the presence of Au-NPs. Strong quenching of the emission was observed in addition to a change in the color due to simultaneous aggregation, confirmed by a positive average Z-potential of $(20 \pm 5) \mathrm{mV}$.

Supplementary Materials: The following are available online at http://www.mdpi.com/2227-9040/6/3/26/s1, Synthesis of compounds 1 and 2; Spectroscopy characterization of compound 2 in different solvents; Spectroscopy characterization of the free fluorescein, $\mathbf{1}$ and $\mathbf{2}$ in alkaline solutions; and Time-resolved photoluminescence measurements: Experimental setup. Scheme S1: Synthesis of compounds $\mathbf{1}$ and $\mathbf{2}$ in $86 \%$ and $90 \%$ yields are presented respectively. Figure S1: (a) Absorbance and (b) normalized emission spectra of the compound 2 in different solvents (concentration of $1 \times 10^{-5} \mathrm{~mol} / \mathrm{L}$ ): (1) THF, (2) ethanol, (3) acetonitrile and (4) DMSO. Figure S2: Absorbance and emission spectra for compound 1 (a), compound 2 (b) and fluorescein (c) in alkaline water pH $12.8\left(\lambda_{\mathrm{e}}=430 \mathrm{~nm}\right)$. Figure S3: Time-resolved photoluminescence setup. $\mathrm{F}(\mathrm{t})$ is photon time distribution obtained from photomultiplier detector using a time-correlated single-photon counting (TCSPC). Figure S4: Lifetime measurements of (a) compound 1 in alkaline aqueous solutions (concentration of $1 \times 10^{-5} \mathrm{~mol} / \mathrm{L}$ ) and (b) Ludox (Time calibration is $5.487 \times 10^{-11} \mathrm{~s} / \mathrm{ch}$ ). Fitting the experimental results, the parameters $\tau_{1}=(4.057 \pm 0.005) \mathrm{ns}, \mathrm{B} 1=100$ Rel. Ampl., and $\chi^{2}=1.01$ were obtained.

Author Contributions: Synthesis of Probes 1 and 2, A.C.G.; Conceptualization, V.P., C.L. and A.A.D.S.; Methodology, V.P. and A.C.G.; Writing-Original Draft Preparation, V.P. and C.L.; Writing-Review \& Editing, V.P.; C.L. and A.A.D.S.; Visualization, V.P. and A.C.G.; Supervision, C.L. and A.A.D.S.; Funding Acquisition, V.P., C.L. and A.A.D.S..

Acknowledgments: V.P. and A.C.G. thank Conselho Nacional de Desenvolvimento Científico e Tecnológico (CNPq)/Brazil for postdoctoral and Ph.D. Grants, respectively. C.L. thanks the CNPq program Science without borders 2014-2016 for the "Special Visitant Researcher" Grant (Brazil), CNPq and Fundação de Amparo à Pesquisa do Estado de Minas Gerais (FAPEMIG). Financial support from the Scientific PROTEOMASS Association (Portugal), LAQV/REQUIMTE is acknowledged. All authors are also grateful for the financial and structural support provided by the University of São Paulo through the NAP-CatSinQ (Research Core in Catalysis and Chemical Synthesis), Fundação de Amparo à Pesquisa do Estado de São Paulo (FAPESP) and Coordenação de Aperfeiçoamento de Pessoal de Nível Superior (CAPES). We thank Javier Fernandez-Lodeiro for synthesizing the gold nanoparticles used in this study.

Conflicts of Interest: The authors declare no conflict of interest.

\section{References}

1. Burchak, O.N.; Mugherli, L.; Chatelain, F.; Balakirev, M.Y. Fluorescein-Based Amino Acids for Solid Phase Synthesis of Fluorogenic Protease Substrates. Bioorg. Med. Chem. 2006, 14, 2559-2568. [CrossRef] [PubMed]

2. Oliveira, E.; Bértolo, E.; Núñez, C.; Pilla, V.; Santos, H.M.; Fernández-Lodeiro, J.; Fernández-Lodeiro, A.; Djafari, J.; Capelo, J.L.; Lodeiro, C. Green and Red Fluorescent Dyes for Translational Applications in Imaging and Sensing Analytes: A Dual-Color Flag. ChemistryOpen 2018, 7, 9-52. [CrossRef] [PubMed]

3. Xiong, X.; Song, F.; Wang, J.; Zhang, Y.; Xue, Y.; Sun, L.; Jiang, N.; Gao, P.; Tian, L.; Peng, X. Thermally Activated Delayed Fluorescence of Fluorescein Derivative for Time-Resolved and Confocal Fluorescence Imaging. J. Am. Chem. Soc. 2014, 136, 9590-9597. [CrossRef] [PubMed]

4. Zheng, H.; Zhan, X.Q.; Bian, Q.N.; Zhang, X.J. Advances in Modifying Fluorescein and Rhodamine Fluorophores as Fluorescent Chemosensors. Chem. Commun. 2013, 49, 429-447. [CrossRef] [PubMed]

5. Sjöback, R.; Nygren, J.; Kubista, M. Absorption and Fluorescence Properties of Fluorescein. Spectrochim. Acta A 1995, 51, L7-L21. [CrossRef]

6. Zhang, X.F.; Zhang, J.; Liu, L. Fluorescence Properties of Twenty Fluorescein Derivatives: Lifetime, Quantum Yield, Absorption and Emission Spectra. J. Fluoresc. 2014, 24, 819-826. [CrossRef] [PubMed]

7. Barba-Bom, A.; Costero, A.M.; Gil, S.; Parra, M.; Soto, J.; Martínez-Máñez, R.; Sancenón, F. A New Selective Fluorogenic Probe for Trivalent Cations. Chem. Commun. 2012, 48, 3000-3002. [CrossRef] [PubMed] 
8. Song, A.; Zhang, J.; Zhang, M.; Shen, T.; Tang, J. Spectral Properties and Structure of Fluorescein and its Alkyl Derivatives in Micelles. Colloids Surf. A Physicochem. Eng. Asp. 2000, 167, 253-262. [CrossRef]

9. Martin, M.M.; Lindqvist, L. The pH Dependence of Fluorescein Fluorescence. J. Lumin. 1975, 10, 381-390. [CrossRef]

10. Martin, E.; Pardo, A.; Guijarro, M.S.; Fernandez-Alonso, J.I. Photophysics Properties of Fluorescein in Alcoholic Medium for Different pH. J. Mol. Struct. 1986, 142, 197-200. [CrossRef]

11. Zhao, Z.G.; Shen, T.; Xu, H.J. The Absorption and Structure of Fluorescein and its Ethyl Derivatives in Various Solutions. Spectrochim. Acta A 1989, 45, 1113-1116. [CrossRef]

12. Song, A.; Wu, T.; Chen, S.; Zhang, M.; Shen, T. Syntheses and Photophysical Properties of Amphiphilic Dyads of Fluorescein and Carbazole Linked with a Flexible or Semi-rigid Bridge. Dyes Pigments 1998, 39, 371-382. [CrossRef]

13. Martin, M.M. Hydrogen Bond Effects on Radiationless Electronic Transitions in Xanthene Dyes. Chem. Phys. Lett. 1975, 35, 105-111. [CrossRef]

14. Klonis, N.; Clayton, A.H.A.; Voss, E.W., Jr.; Sawyer, W.H. Spectral Properties of Fluorescein in Solvent-Water Mixtures: Applications as a Probe of Hydrogen Bonding Environments in Biological Systems. Photochem. Photobiol. 1998, 67, 500-510. [CrossRef] [PubMed]

15. Mchedlov-Petrossyan, N.O.; Ivanov, V.V. Effect of the Solvent on the Absorption Spectra and Protonation of Fluorescein Dye Anions. Russ. J. Phys. Chem. A 2007, 81, 112-115. [CrossRef]

16. Homocianu, M.; Airinei, A.; Dorohoi, D.O. Solvent Effects on the Electronic Absorption and Fluorescence Spectra. J. Adv. Res. Phys. 2017, 2, 011105. Available online: http://stoner.phys.uaic.ro/jarp/index.php? journal=jarp\&page $=$ article\&op $=$ view $\&$ path $\% 5 B \% 5 \mathrm{D}=30$ (accessed on 8 May 2018).

17. Magde, D.; Rojas, G.E.; Seybold, P.G. Solvent Dependence of the Fluorescence Lifetimes of Xanthene Dyes. Photochem. Photobiol. 1999, 70, 737-744. [CrossRef]

18. Gidwani, M.S.; Menon, S.K.; Agrawal, Y.K. Fluorescence and Lasing Characteristics of Fluorescein Calix[4]aryl Hydroxamic Acid. Indian J. Chem. Technol. 2003, 10, 519-524. Available online: http:/ / nopr.niscair.res.in/handle/ $123456789 / 22786$ (accessed on 8 May 2018).

19. Bindhu, C.V.; Harilal, S.S.; Nampoori, V.P.N.; Vallabhan, C.P.G. Solvent Effect on Absolute Fluorescence Quantum Yield of Rhodamine 6G Determined Using Transient Thermal Lens Technique. Mod. Phys. Lett. B 1999, 13, 563-576. [CrossRef]

20. Sinha, S.; Ray, A.; Dasgupta, K. Solvent Dependent Nonlinear Refraction in Organic Dye Solution. J. Appl. Phys. 2000, 87, 3222-3226. [CrossRef]

21. Magde, D.; Wong, R.; Seybold, P.G. Fluorescence Quantum Yields and Their Relation to Lifetimes of Rhodamine 6G and Fluorescein in Nine Solvents: Improved Absolute Standards for Quantum Yields. Photochem. Photobiol. 2002, 75, 327-334. [CrossRef]

22. Gonçalves, A.C.; Pilla, V.; Oliveira, E.; Santos, S.M.; Capelo, J.L.; Dos Santos, A.A.; Lodeiro, C. The Interaction of $\mathrm{Hg}^{2+}$ and Trivalent Ions with Two New Fluorescein Bio-inspired Dual Colorimetric/Fluorimetric Probes. Dalton Trans. 2016, 45, 9513-9522. [CrossRef] [PubMed]

23. Akshath, U.S.; Bhatt, P. Gold Nanoparticle Synthesis Coupled to Fluorescence Turn-on for Sensitive Detection of Formaldehyde using Formaldehyde Dehydrogenase. RSC Adv. 2016, 6, 54777-54784. [CrossRef]

24. Yang, G.; Xiang, S.; Zhang, K.; Gao, D.; Zeng, C.; Zhao, F. Breast Cancer Imaging with Fluoresce in Isothiocyanate-Modified Gold Nanoparticles In-Vidro and In-Vivo. Int. J. Clin. Exp. Med. 2016, 9, 753-759. Available online: http:/ / www.ijcem.com/V9_No2.html (accessed on 8 May 2018).

25. Tao, H.; Liao, X.; Xu, M.; Xie, X.; Zhong, F.; Yi, Z. Detection of Immunoglobulin G based on Nanoparticle Surface Energy Transfers from Fluorescein Isothiocyanate to Gold Nanoparticles. Anal. Methods 2014, 6, 2560-2565. [CrossRef]

26. Barnoy, E.A.; Fixler, D.; Popovtzer, R.; Nayhoz, T.; Ray, K. An Ultra-Sensitive Dual-Mode Imaging System Using Metal-Enhanced Fluorescence in Solid Phantoms. Nano Res. 2015, 8, 3912-3921. [CrossRef] [PubMed]

27. Chen, C.; Zhao, D.; Sun, J.; Yang, X. A Dual-Mode Signaling Response of a AuNP-Fluorescein Based Probe for Specific Detection of Thiourea. Analyst 2016, 141, 2581-2587. [CrossRef] [PubMed]

28. Sironi, L.; Freddi, S.; D'Alfonso, L.; Collini, M.; Gorletta, T.; Soddu, S.; Chirico, G. p53 Detection by Fluorescence Lifetime on a Hybrid Fluorescein Isothiocyanate Gold Nanosensor. J. Biomed. Nanotechnol. 2009, 5, 683-691. [CrossRef] [PubMed] 
29. Yu, K.K.; Li, K.; Qin, H.H.; Zhou, Q.; Qian, C.H.; Liu, Y.H.; Yu, X.Q. Construction of pH-Sensitive "Submarine" Based on Gold Nanoparticles with Double Insurance for Intracellular pH Mapping, Quantifying of Whole Cells and in Vivo Applications. ACS Appl. Mater. Interfaces 2016, 8, 22839-22848. [CrossRef] [PubMed]

30. Fernández-Lodeiro, J.; Núñez, C.; Oliveira, E.; Capelo, J.L.; Lodeiro, C. 1D Chain Fluorescein-Functionalized Gold and Silver Nanoparticles as New Optical Mercury Chemosensor in Aqueous Media. J. Nanopart. Res. 2013, 15, 1828. [CrossRef]

31. Hoop, M.; Mushtaq, F.; Hurter, C.; Chen, X.Z.; Nelson, B.J.; Pané, S. A Smart Multifunctional Drug Delivery Nanoplatform for Targeting Cancer Cells. Nanoscale 2016, 8, 12723-12728. [CrossRef] [PubMed]

32. Fernández-Lodeiro, J.; Rodríguez-González, B.; Santos, H.M.; Bértolo, E.; Capelo, J.L.; Dos Santos, A.A.; Lodeiro, C. Unraveling the Organotellurium Chemistry Applied to the Synthesis of Gold Nanomaterials. ACS Omega 2016, 1, 1314-1325. [CrossRef]

33. Montalti, M.; Credi, A.; Prodi, L.; Gandolfi, M.T. Handbook of Photochemistry, 3rd ed.; Taylor \& Francis: Boca Raton, FL, USA, 2006; ISBN 9780824723774.

34. Wypych, G. Handbook of Solvents; ChemTec Publishing and William Andrew Inc.: Toronto, ON, Canada; New York, NY, USA, 2001; ISBN 1-895198-24-0.

35. Mata, R.A.; Costa Cabral, B.J. Structural, Energetic, and Electronic Properties of (CH3CN)2-8 Clusters by Density Functional Theory. J. Mol. Struct. (THEOCHEM) 2004, 673, 155-164. [CrossRef]

36. Aaron, J.J.; Maafi, M.; Párkányi, C.; Boniface, C. Quantitative Treatment of the Solvent Effects on the Electronic Absorption and Fluorescence Spectra of Acridines and Phenazines. The Ground and First Excited Singlet-State Dipole Moments. Spectrochim. Acta 1995, 51, 603-615. [CrossRef]

37. Ali, M.; Dutta, P.; Pandey, S. Effect of Ionic Liquid on Prototropic and Solvatochromic Behavior of Fluorescein. J. Phys. Chem. B 2010, 114, 15042-15051. [CrossRef] [PubMed]

38. Al-Tememee, N.A.A.; Al-Ani, S.K.J.; AbdAlfahdaw, A.A. Effect of Solvents on the Dipole Moments and Fluorescence Quantum Yield of Rhodamine Dyes. ISESCO J. Sci. Technol. 2013, 9, 34-42. Available online: https:/ / www.isesco.org.ma/ISESCO_Technology_Vision/NUM16/doc/5.pdf (accessed on 8 May 2018).

39. Alvarez-Pez, J.M.; Ballesteros, L.; Talavera, E.; Yguerabide, J. Fluorescein Excited-State Proton Exchange Reactions: Nanosecond Emission Kinetics and Correlation with Steady-State Fluorescence Intensity. J. Phys. Chem. A 2001, 105, 6320-6332. [CrossRef]

40. Ueno, T.; Urano, Y.; Setsukinai, K.; Takakusa, H.; Kojima, H.; Kikuchi, K.; Ohkubo, K.; Fukuzumi, S.; Nagano, T. Rational Principles for Modulating Fluorescence Properties of Fluorescein. J. Am. Chem. Soc. 2004, 126, 14079-14085. [CrossRef] [PubMed]

41. Strickler, S.J.; Berg, R.A. Relationship Between Absorption Intensity and Fluorescence Lifetime of Molecules. J. Chem. Phys. 1962, 37, 814-822. [CrossRef]

42. Zhang, X.F. The Effect of Phenyl Substitution on the Fluorescence Characteristics of Fluorescein Derivatives via Intramolecular Photoinduced Electron Transfer. Photochem. Photobiol. Sci. 2010, 9, 1261-1268. [CrossRef] [PubMed]

43. Tamulis, A.; Tamuliene, J.; Balevicius, M.L.; Rinkevicius, Z.; Tamulis, V. Quantum Mechanical Studies of Intensity in Electronic Spectra of Fluorescein Dianion and Monoanion Forms. Struct. Chem. 2003, 14, $643-648$. [CrossRef]

44. Batistela, V.R.; da Costa Cedran, J.; de Oliveira, H.P.M.; Scarminio, I.S.; Ueno, L.T.; da Hora Machado, A.E.; Hioka, N. Protolytic Fluorescein Species Evaluated Using Chemometry and DFT Studies. Dyes Pigments 2010, 86, 15-24. [CrossRef]

45. Togashi, D.M.; Szczupak, B.; Ryder, A.G.; Calvet, A.; O’Loughlin, M. Investigating Tryptophan Quenching of Fluorescein Fluorescence under Protolytic Equilibrium. J. Phys. Chem. A 2009, 113, 2757-2767. [CrossRef] [PubMed]

46. Boens, N.; Qin, W.; Basarić, N.; Hofkens, J.; Ameloot, M.; Pouget, J.; Lefèvre, J.P.; Valeur, B.; Gratton, E.; VandeVen, M.; et al. Fluorescence Lifetime Standards for Time and Frequency Domain Fluorescence Spectroscopy. Anal. Chem. 2007, 79, 2137-2149. [CrossRef] [PubMed]

47. Fernández-Lodeiro, J.; Nuñez, C.; Fernández-Lodeiro, A.; Oliveira, E.; Rodríguez-González, B.; Dos Santos, A.A.; Capelo, J.L.; Lodeiro, C. New-coated Fluorescent Silver Nanoparticles with a Fluorescein Thiol Esther Derivative: Fluorescent Enhancement upon Interaction with Heavy Metal Ions. J. Nanopart. Res. 2014, 16, 2315. [CrossRef] 
48. Kumar, A.; De, A.; Saxena, A.; Mozumdar, S. Environmentally Benign Synthesis of Positively Charged, Ultra-Low Sized Colloidal Gold in Universal Solvent. Adv. Nat. Sci. Nanosci. Nanotechnol. 2014, 5, 025017. [CrossRef]

49. Lu, G.W.; Gao, P. Handbook of Non-Invasive Drug Delivery Systems; Emulsions and Microemulsions for Topical and Transdermal Drug Delivery, 1st ed.; William Andrew: Norwich, NY, USA, 2010; pp. 59-94. ISBN 9780815520252.

50. Guo, J.; Armstrong, M.J.; O’Driscoll, C.M.; Holmes, J.D.; Rahme, K. Positively Charged, Surfactant-Free Gold Nanoparticles for Nuclei Acid Delivery. RSC Adv. 2015, 5, 17862-17871. [CrossRef]

(C) 2018 by the authors. Licensee MDPI, Basel, Switzerland. This article is an open access article distributed under the terms and conditions of the Creative Commons Attribution (CC BY) license (http://creativecommons.org/licenses/by/4.0/). 